\title{
Alizarin and Chrysazin Inhibit Biofilm and Hyphal Formation by Candida albicans
}

\author{
Ranjith Kumar Manoharan, Jin-Hyung Lee, Yong-Guy Kim and Jintae Lee* \\ School of Chemical Engineering, Yeungnam University, Gyeongsan, South Korea
}

Candida albicans is one of the most common pathogen causes fungal infections. This opportunistic pathogen can form biofilms comprised of yeast, hyphae and pseudo hyphal elements, and the hyphal form C. albicans considered as probable virulence factor. We investigated the antibiofilm activities of 13 quinones and anthraquinones related compounds against $C$. albicans biofilms by using crystal violet and 2,3-bis (2-Methoxy-4-Nitro-5-Sulfo-phenyl)-2H-Tetrazolium-5-Carboxanilide (XTT) reduction assays to assess inhibitions of biofilm growth. Morphological changes in biofilms and biofilm thicknesses were determined by scanning electron microscopy and confocal laser scanning microscopy, respectively. It was found alizarin (1,2-dihydroxyanthraquinone) and chrysazin (1,8-dihydroxyanthraquinone) suppressed C. albicans biofilm formation. Interestingly, alizarin and chrysazin at only $2 \mu \mathrm{g} / \mathrm{ml}$ effectively inhibited hyphal formation and prolonged the survival of C. albicans infected Caenorhabditis elegans, thus showing a distinct antivirulent potential. A structural activity relationship study of alizarin and 6 other anthraquinones showed the presence of a hydroxyl group at C-1 position which is important for antibiofilm and antifilamentation activities. Transcriptomic analyses revealed that alizarin downregulated the expression of several hypha-specific and biofilm related genes (ALS3, ECE1, ECE2, and RBT1). Furthermore, unlike the commercial antifungal drug fluconazole, no acute toxic effect was observed when uninfected nematodes were exposed to alizarin at concentrations up to $1 \mathrm{mg} / \mathrm{ml}$. The results of this study indicate alizarin suppresses the virulence of C. albicans in vivo which suggests alizarin may be considered as a potential candidate for further investigations to develop antifungal agent against fungal pathogen in vivo.

Keywords: C. albicans, anthraquinone, alizarin, chrysazin, biofilm formation, hyphal formation

\section{INTRODUCTION}

Received: 14 July 2017 Accepted: 29 September 2017 Published: 16 October 2017

Citation:

Manoharan RK, Lee J-H, Kim Y-G and Lee J (2017) Alizarin and Chrysazin Inhibit Biofilm and Hyphal Formation by Candida albicans. Front. Cell. Infect. Microbiol. 7:447. doi: 10.3389/fcimb.2017.00447

Candida albicans is an opportunistic fungal pathogen and the cause of systemic infections predominantly in immunocompromised individuals and in patients with an implanted device, such as, a catheter, cardiac pacemaker, or heart valve (Ramage et al., 2005; Sardi et al., 2013). C. albicans can grow as oval budding yeasts, as continuous septate hyphae, or as pseudohyphae, and all three of these morphological forms are usually observed in infected tissues. C. albicans can easily colonizes on medical devices such as gastrointestinal tract and intravascular catheters, artificial heart valves, and contact lenses and cause infections with high mortality rates (Sardi et al., 2013). Identified virulence factors of Candida infection include initial adhesion and the ability to form surface biofilms, the latter of which causes yeast cell transition to their hyphal form 
(Rajasekharan et al., 2015; Carradori et al., 2016). Accordingly, the suppressions of biofilm formation and hyphal transition are considered as effective strategies for countering Candida virulence and pathogenesis (Gauwerky et al., 2009). The dimorphologic states (yeast and hypha) of C. albicans cells and the inhibition of phenotype switching between yeast and hyphae presents a possible means of developing antifungal agents. Furthermore, the effectivenesses of available antifungals are limited by the development of resistant Candida biofilms and by their toxicities (Taff et al., 2013; Sandai et al., 2016). Thus, there is an urgent need for new antifungals that are effective against Candida biofilms.

Several potential molecules like linalool (Souza et al., 2016; Manoharan et al., 2017a), geraniol (Cardoso et al., 2016), nerolidol (Curvelo et al., 2014), sophorolipid (Haque et al., 2016), gymnemic acid (Vediyappan et al., 2013), and phenazines (Morales et al., 2013) have been reported to inhibit biofilm formation by Candida, and a few small molecules, such as, shearinine, clozapine, buhytrin $\mathrm{A}$, and $\alpha$-longipinene, have been reported to inhibit C. albicans yeast to hypha transition (Grald et al., 2012; Pierce et al., 2015; Reen et al., 2016; Manoharan et al., 2017a). Importantly, compounds that inhibit biofilm formation and hyphal growth without affecting growth or planktonic cell viability, which minimize resistance, might be useful antibiofilm agents. Few researchers have reported several anthraquinones, such as, purpurin, emodin, chyrsophanol, rubiadin, and rhein, with antifungal and antibiofilm activities against $C$. albicans (Xiang et al., 2008; Kang et al., 2010; Marioni et al., 2016; Janeczko et al., 2017). Previously, we investigated the antibiofilm activities of 560 phytochemicals against Staphylococcus aureus. Of these several anthraquinone derivatives had showed biofilm inhibition against S. aureus (Lee et al., 2016). Hence, the present study was designed to investigate the effect of anthraquinone derivatives against $C$. albicans virulence.

In the present study, we report the abilities of anthraquinone derivatives to inhibit biofilm formation without affecting the planktonic growth of $C$. albicans using crystal violet and XTT [2,3-bis(2-methoxy-4-nitro-5-sulfo-phenyl)-2Htetrazolium- 5-carboxanilide] reduction assays. Cell morphology and phenotypic switching of $C$. albicans cells were observed by scanning electron microscopy (SEM) and biofilm thicknesses was measured by confocal laser scanning microscopy (CLSM). In addition, potential compounds were evaluated with respect to hyphal inhibition and anti-biofilm efficacy using a Caenorhabditis elegans (a nematode) model.

\section{MATERIALS AND METHODS}

\section{Strains, Cultivation, Chemicals, and Minimum Inhibitory Concentrations}

The standard C. albicans strains DAY185, ATCC10231, ATCC18804, and ATCC24433 used in this study were obtained from the Korean Culture Center of Microorganisms (http://www. $\mathrm{kccm}$.or.kr/). Streaking and subculturing of C. albicans strains were performed using potato dextrose agar (PDA) or potato dextrose broth (PDB), unless otherwise specified. C. albicans strain was preserved at $-80^{\circ} \mathrm{C}$ in $1 \mathrm{ml}$ of $\mathrm{PDB}$ supplemented with $30 \%$ glycerol stock, and when needed, streaked on PDA plates. Plates were incubated for $48 \mathrm{~h}$ at $37^{\circ} \mathrm{C}$, and a fresh single colony was then inoculated into $25 \mathrm{ml}$ of $\mathrm{PDB}$ and cultured overnight at $37^{\circ} \mathrm{C}$. The strain S. aureus 6538 was maintained and cultured in LB medium. All 13 compounds tested, namely, alizarin, alizarin red, anthraflavic acid, anthraquinone, chrysazin, $(+)$-catechin, $(+)$-catechin hydrate, emodin, 1-hydroxyanthra9,10-quinone, hydroquinone, purpurin, pyrocatechol, and quinalizarin were purchased from Sigma-Aldrich (St. Louis, USA) and dissolved in dimethyl sulfoxide (DMSO), which did not exceed $0.1 \%$ (vol $/ \mathrm{vol}$ ) in any experiment. To determine cell growths, turbidities were measured at $620 \mathrm{~nm}$ using a spectrophotometer (UV-160, Shimadzu, Japan). Minimum inhibitory concentrations (MICs) were determined using the Clinical Laboratory Standards Institute (CLSI) broth dilution method with slight modification (Alastruey-Izquierdo et al., 2015), using 96-well polystyrene plates (SPL Life Sciences, Korea). C. albicans cells were cultured overnight in PDB medium and diluted to reach a final concentration of $10^{5} \mathrm{CFU} / \mathrm{mL}$ and added to the wells in the presence of varying concentrations $(\mathrm{w} / \mathrm{v})$ of tested compounds at $24 \mathrm{~h}$ at $37^{\circ} \mathrm{C}$. MIC was defined as the lowest concentration that inhibited microbial growth by at least $80 \%$, as assessed by spectrophotometry $(620 \mathrm{~nm})$ and colony counting. MICs of tested compounds are expressed as percentages (v/v or w/v).

\section{Assays of Biofilm Inhibition and Biofilm Dispersal}

Candida biofilms were prepared on 96-well polystyrene plates, as previously reported (Lee et al., 2011). Briefly, overnight cultures of $C$. albicans strains were inoculated into PDB (total volume $300 \mu \mathrm{l}$ ) at an initial turbidity of 0.1 at $600 \mathrm{~nm}$ and cultured with or without test compounds at varying concentrations for $24 \mathrm{~h}$ without shaking at $37^{\circ} \mathrm{C}$. To perform biofilm inhibition assay in mixed cultures, overnight cultures of $C$. albicans and $S$. aureus strains were equally inoculated into medium containing PDB and LB (final volume $300 \mu \mathrm{l}$ ) at an initial turbidity of 0.1 at $600 \mathrm{~nm}$ and cultured as mentioned above.

To investigate the effects of the anthraquinones alizarin and chrysazin on biofilm disruption, C. albicans biofilms were prepared on 96-well polystyrene plates for $24 \mathrm{~h}$ at $37^{\circ} \mathrm{C}$, as described above. Briefly, wells were washed twice with PBS and fresh PDB medium $(300 \mu \mathrm{l})$ containing different concentrations of compounds were added to plates, which were then further incubated for $24 \mathrm{~h}$ at $37^{\circ} \mathrm{C}$. Biofilm formation was quantified after washing three times with $\mathrm{H}_{2} \mathrm{O}$ (to remove all non-adherent cells), staining with crystal violet for $20 \mathrm{~min}$, rinsing three times with $\mathrm{H}_{2} \mathrm{O}$, and extracting the crystal violet with $95 \%$ ethanol. Absorbance was measured at $570 \mathrm{~nm}$, and results are presented as the averages of at least six replicates.

\section{Biofilm Metabolic Activity-XTT Reduction Assay}

A colorimetric XTT [2,3-bis(2-methoxy-4-nitro-5-sulfophenyl)2H-tetrazolium-5-carboxanilide sodium salt] reduction assay 
was performed using established procedures (Ramage et al., 2001; Nett et al., 2011). Briefly, overnight cultures of C. albicans strains were inoculated into PDB (total volume $300 \mu \mathrm{l}$ ) at an initial turbidity of 0.1 at $600 \mathrm{~nm}$ and cultured with or without alizarin or chrysazin at different concentrations for $24 \mathrm{~h}$ without shaking at $37^{\circ} \mathrm{C}$. A XTT reduction kit (Sigma-Aldrich, St. Louis, USA) was used to measure the metabolic activities of biofilm cells. XTT and menadione solutions were mixed at 20:1 (v/v) immediately prior to the assay. PBS was then added to XTT-menadione solution $(3.76: 1 \mathrm{v} / \mathrm{v})$ and $200 \mu \mathrm{l}$ of this mix was added to each well containing pre-washed biofilms, and incubated in the dark for $3 \mathrm{~h}$ at $37^{\circ} \mathrm{C}$. The colored supernatant $(100 \mu \mathrm{l})$ so obtained was transferred to new microtiter plates, and optical densities were measured at $450 \mathrm{~nm}$. Similarly, planktonic cell viability was measured by using culture supernatants.

\section{Assay of C. albicans Hyphal Development in Liquid Media}

Overnight cultures of C. albicans DAY 185 were inoculated into the hyphae-inducing media RPMI-1640 medium with or without alizarin or chrysazin (both at $2 \mu \mathrm{g} / \mathrm{ml}$ ) for $24 \mathrm{~h}$ with shaking at $37^{\circ} \mathrm{C}$. Aliquots of fungal cells were harvested at different times $(0,6$, or $24 \mathrm{~h})$ and visualized under bright field using the iRiS ${ }^{\mathrm{TM}}$ Digital Cell Imaging System (Logos Bio Systems, Korea).

\section{Confocal Laser Scanning Microscopy of Biofilm Formation}

C. albicans cells were cultured in 96-well polystyrene plates (SPL Life Sciences, Korea) without shaking in the absence or presence of alizarin or chrysazin. Planktonic cells were then removed by washing with PBS buffer three times. C. albicans cells were stained with carboxyfluorescein diacetate succinimidyl ester (a minimally fluorescent lipophile; Catalog \#: C34554, Invitrogen, Molecular Probes, Inc, Eugene, USA; Weston and Parish, 1990), which becomes highly fluorescent when it loses its acetyl groups due to the action of esterases in cells. Biofilms at the bottom of plate was visualized using an (a $488 \mathrm{~nm}$ ) Ar laser (emission wavelength $500-550 \mathrm{~nm}$ ) under a confocal laser microscope (Nikon Eclipse Ti, Tokyo) equipped with a $20 \times$ objective (Kim et al., 2012). Color confocal images were constructed using NISElements $\mathrm{C}$ version 3.2 (Nikon eclipse). For each experiment, at least 10 random positions in two independent cultures were examined.

\section{Observations of Hyphae by Scanning Electron Microscopy (SEM)}

SEM was used to observe hyphal formation, as previously described (Lee et al., 2014). Briefly, a nylon membrane was cut into $0.5 \times 0.5 \mathrm{~cm}$ pieces and one piece was placed per well in 96-well plates containing $200 \mu \mathrm{L}$ cells/well of turbidity 0.05 at $600 \mathrm{~nm}$. Cells were incubated in the presence or absence (untreated control) of alizarin or chrysazin at $37^{\circ} \mathrm{C}$ for $24 \mathrm{~h}$ without shaking. Cells were then fixed with glutaraldehyde (2.5\%) and formaldehyde (2\%) for $24 \mathrm{~h}$, and post fixed in osmium tetroxide and dehydrated in a series of ethanol solutions $(50,70$, 80, 90, 95, and 100\%), and isoamyl acetate. After critical-point drying, cells fixed onto nylon membranes were examined under a S-4200 scanning electron microscope (Hitachi, Japan) at a voltage of $15 \mathrm{kV}$ and magnifications ranging from $\times 2,000$ to $\times 10,000$.

\section{RNA Isolation and Quantitative Real-Time PCR (qRT-PCR)}

For transcriptional analysis, C. albicans was inoculated into $25 \mathrm{ml}$ of PDB broth in $250 \mathrm{ml}$ shake flasks at a starting $\mathrm{OD}_{600}$ of 0.1 , and then cultured at $37^{\circ} \mathrm{C}$ for $4 \mathrm{~h}$ with agitation $(250 \mathrm{rpm})$ in the presence or absence of alizarin or chrysazin $(2 \mu \mathrm{g} / \mathrm{ml})$. RNase inhibitor (RNAlater, Ambion, TX, USA) was added to prevent RNA degradation. Total RNA was isolated using a hot acidic phenol method (Amin-ul Mannan et al., 2009) and further proceed to clean up this RNA with Qiagen RNeasy mini Kit (Valencia, CA, USA). qRT-PCR was used to determine the transcription levels of hypha- and biofilm-related genes [HYR1, EFG1, ECE1, ECE2, ALS1, ALS3 (or called HWP1), $E E D 1$, and $R B T 1]$ in $C$. albicans treated or not with alizarin or chrysazin. Gene specific primers were used and RDN18 was used as housekeeping controls (Supplementary Table 1). The qRT-PCR method used has been previously described (Lee et al., 2011). qRT-PCR was performed using a SYBR Green master mix (Applied Biosystems, Foster City, USA) and an ABI StepOne Real-Time PCR System (Applied Biosystems) on two independent cultures.

\section{Candida Infection in the Caenorhabditis elegans Model}

To investigate the effects of alizarin or chrysazin or purpurin on the virulence of $C$. albicans, the nematode $C$. elegans wild type strain N2 Bristol CF512 fer-15(b26); fem-1(hc17) (Murphy et al., 2003; Oh et al., 2012) with loss of sex-determining protein Fem-1 and age determining protein Fer-15 was infected with C. albicans as previously described (Manoharan et al., 2017a). Briefly, a freshly prepared overnight $C$. albicans culture $(100 \mu \mathrm{l})$ was spread onto a lawn on PDA plates and incubated for $48 \mathrm{~h}$ at $37^{\circ} \mathrm{C}$. Synchronized adult were then allowed to feed on the $C$. albicans yeast lawn for $4 \mathrm{~h}$ at $25^{\circ} \mathrm{C}$ when worms were collected and washed three times with sterile M9 buffer. Approximately 10 worms were then pipetted into single wells of 96-well plates containing PDB medium and treated with solutions $(300 \mu \mathrm{l})$ of investigated compounds at final concentrations ranging from 0.2 to $2 \mu \mathrm{g} / \mathrm{ml}$. Controls were treated with medium alone. For toxicity assays, 10 non-infected worms were pipetted into single wells of a 96-well dish containing M9 buffer and solutions of the compounds $(300 \mu \mathrm{l})$ were added to final concentrations of 1 or $2 \mathrm{mg} / \mathrm{ml}$. Plates were then incubated at $25^{\circ} \mathrm{C}$ for 4 days with gentle shaking. Three independent experiments were conducted in triplicate. Results are expressed as percentages of alive or dead worms by gently touching them with a platinum wire after 4 days of incubation, and results were obtained using an iRiS ${ }^{\mathrm{TM}}$ Digital Cell Imaging System (Logos Bio Systems, Korea).

\section{Statistical Analysis}

In all cases, at least two independent experiments were conducted, and results are expressed as means \pm standard deviations. The student's $t$-test was used to determine the 
significances of differences between treated and non-treated samples. Statistical significance was accepted for $p<0.05$, and in the figures significant changes are indicated by asterisks.

\section{RESULTS}

\section{Effects of Anthraquinone and Quinone Related Compounds on C. albicans Biofilm Formation}

The antibiofilm efficacies of the 13 compounds (Figure 1A) tested were examined using C. albicans on 96-well polystyrene plates. Of these compounds, the anthraquinones alizarin, chrysazin, purpurin, 1-hydroxyanthra-9,10-quinone, emodin, and quinalizarin were found to be effective at $10 \mu \mathrm{g} / \mathrm{ml}$ against C. albicans biofilms without affecting planktonic cell growth (Figure 1B). Nevertheless, anthraquinone, pyrocatechol, and alizarin red showed significant biofilm inhibition at $50 \mu \mathrm{g} / \mathrm{ml}$ (Figure 1B). Further experimentation showed that chrysazin, purpurin, and alizarin significantly reduced biofilm formation by 50,57 , and $82 \%$, respectively, even at $0.5 \mu \mathrm{g} / \mathrm{ml}$ (Figure 1C). Further increases in the concentrations of alizarin, chrysazin, and fluconazole significantly exacerbated biofilm disruption (Figure 2A). In addition, alizarin and chrysazin at $2 \mu \mathrm{g} / \mathrm{ml}$ dramatically reduced biofilm formation by three other $C$. albicans strains (ATCC10231, ATCC18804, ATCC24433) by $\geq 90 \%$. While fluconazole significantly reduced biofilm formation by C. albicans strains ATCC10231 and ATCC24433 by 43 and $72 \%$, respectively at $2 \mu \mathrm{g} / \mathrm{ml}$ (Figure 2B). Our data suggest that alizarin and chrysazin are more effective to inhibit biofilm formation by several C. albicans strains than commercial drug fluconazole. Interestingly, alizarin, chrysazin, and purpurin had significantly reduced mixed biofilm formation by C. albicans and $S$. aureus at 2 and $10 \mu \mathrm{g} / \mathrm{ml}$, while fluconazole had lower activity on mixed biofilms at $10 \mu \mathrm{g} / \mathrm{ml}$ when compared to anthraquinone derivatives (Supplementary Figure 1). Since purpurin has been reported as antibiofilm and antihyphal agent against $C$. albicans (Tsang et al., 2012), our present study was designed and focused only on alizarin and other anthraquinone related compounds for their antihyphal activities.

\section{Effects of Alizarin and Chrysazin on C. albicans Metabolic Activity}

The effects of alizarin and chrysazin on C. albicans biofilms and planktonic cells were quantified using XTT reduction assay and viabilities were calculated by expressing metabolic activities as percentages of non-treated controls. C. albicans metabolic activity was significantly reduced (by $80 \%$ ) by alizarin up to $2 \mu \mathrm{g} / \mathrm{ml}$. However, chrysazin reduced the metabolic activity of $C$. albicans biofilms by $66 \%$ at $2 \mu \mathrm{g} / \mathrm{ml}$ (Figure 3), and alizarin at $10 \mu \mathrm{g} / \mathrm{ml}$ completely removed biofilms (>98\%), while it slightly reduced (25\%) metabolic activity on planktonic cells.

\section{Antimicrobial Activities of Alizarin and Chrysazin}

The antimicrobial activities of alizarin and chrysazin were investigated by measuring minimum inhibitory concentrations
(MIC), which for both compounds were $>2,000 \mu \mathrm{g} / \mathrm{ml}$ against C. albicans. Notably, this MIC was 1,000-times higher than the concentration $(2 \mu \mathrm{g} / \mathrm{ml})$ required for antibiofilm activity for both compounds. The MIC of all quinone and anthraquinone derivatives are given in Table 1. C. albicans DAY185 was found to be resistant to all tested compounds. For example, anthraflavic acid had showed a MIC up to $500 \mu \mathrm{g} / \mathrm{ml}$, several compounds exhibited MIC ranging from 1,000 to $5,000 \mu \mathrm{g} / \mathrm{ml}$. These results confirm that biofilm formation by $C$. albicans was effectively reduced by the antibiofilm activities of alizarin and chrysazin and not by their antifungal activities. These results show that alizarin and chrysazin have fungistatic rather than fungicidal effects on C. albicans.

\section{Alizarin Affected C. albicans Morphology in Biofilms}

Confocal laser scanning microscopy (CLSM) images showed C. albicans formed dense biofilms in non-treated control samples, but that in the presence alizarin at 0.2 and $2 \mu \mathrm{g} / \mathrm{ml}$ biofilm cellular densities and thicknesses were reduced. While no reduction was observed at a chrysazin concentration of $0.2 \mu \mathrm{g} / \mathrm{ml}$, major reduction was observed at $2 \mu \mathrm{g} / \mathrm{ml}$ (Figure 4). Scanning electron microscopy (SEM) showed in addition to reducing biofilm metabolic activity, alizarin also inhibited yeast to hyphal transition. As shown in Figure 5, nontreated control biofilms consisted of mixtures of pseudohyphae and hyphae, and few yeast cells. In contrast, alizarin and chrysazin reduces the length of existing hyphae of $C$. albicans and increased yeast form cells as compared to the untreated control (Figure 5). In addition, alizarin and chrysazin both strongly inhibited biofilm development on polystyrene surfaces (Figures 1, 4) and nylon membrane (Figure 5) as well.

\section{The Effects of Alizarin and Chrysazin on Hyphal Growth in Liquid Media}

Hyphae inducing RPMI medium was used to examine hyphal inhibition by alizarin and chrysazin. Untreated controls showed massive hyphal growth after $6 \mathrm{~h}$, but in the presence of $2 \mu \mathrm{g} / \mathrm{ml}$ alizarin or chrysazin hyphal growth was not observed. When cultured in RPMI containing alizarin or chrysazin at $2 \mu \mathrm{g} / \mathrm{ml}$ for $24 \mathrm{~h}$, fungal cells grew by budding, whereas controls large hyphal cells were observed (Figure 6) Microscopic observations of alizarin or chrysazin treated fungal cells revealed that in addition to reducing metabolic activity in biofilms, both compounds reduced hyphal lengths and inhibited yeast to hyphae transition.

\section{Effect of Alizarin and Chrysazin on the Expression of Hypha and Biofilm Related Genes}

Transcriptional levels of the hypha-specific and biofilm related genes in $C$. albicans were quantified by qRT-PCR. Alizarin at $2 \mu \mathrm{g} / \mathrm{ml}$ significantly downregulated the expression of the hypha specific genes ALS3 (2.4-fold), ECE1 (3.7-fold), ECE2 (6.3fold), and RBT1 (5.8-fold) when compared to their respective controls (Figure 7). Similarly, the expression of ECE1, ECE2, and RBT1 were significantly downregulated by 2 -, 2.3 -, and 2 -fold, 
A<smiles>OC1CCC(O)CC1</smiles><smiles>OC1=CC(O)C2CC(O)C(c3ccc(O)c(O)c3)OC2C1</smiles><smiles>O=C1c2ccccc2C(=O)c2ccccc21</smiles>

Hydroquinone (+)-Catechin hydrate Anthraflavic acid Anthraquinone<smiles>Oc1ccccc1O</smiles><smiles>[O]O</smiles>
Catechin $\mathrm{OH}$

$\mathrm{OH} \mathrm{OHO} \mathrm{OH}$

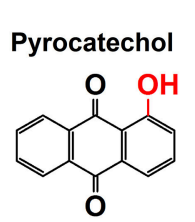

1-hydroxyanthra-9,10- Purpurin<smiles>O=C1c2ccccc2C(=O)C2C(O)=C(O)C=C(O)C12</smiles>

a<smiles>CCOC(=O)C1C2C=C(O)C=C(O)C2C(O)C2C(O)C=C(C)CC12</smiles>

Quinalizarin

$$
\text { Emodin }
$$<smiles>O=C1c2cccc(O)c2C(O)C2C(O)CCCC12</smiles>

Chrysazin<smiles>O=C1c2ccccc2C(=O)c2c1ccc(O)c2O</smiles>

B quinone

音
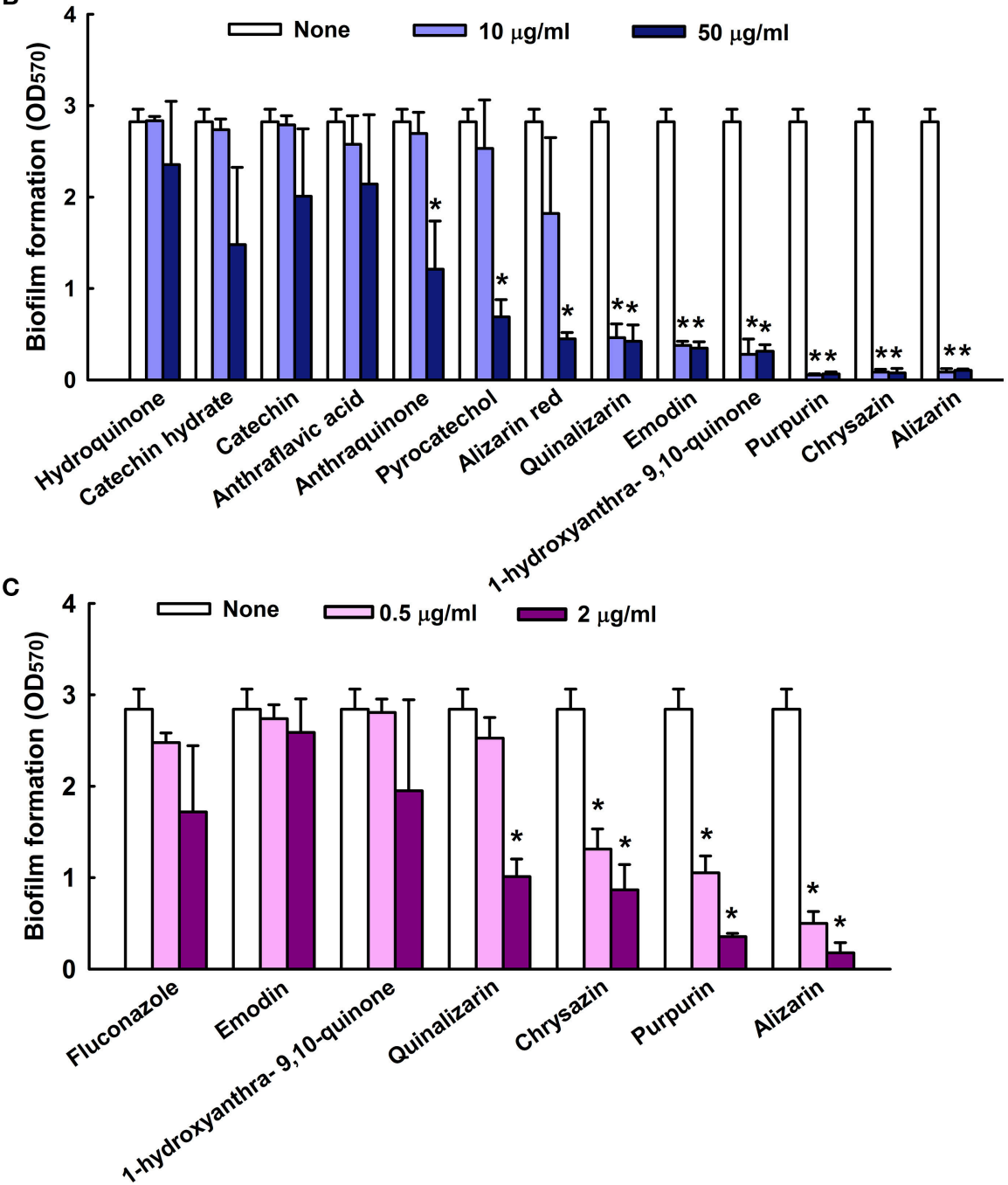

FIGURE 1 | Inhibition of biofilm formation by quinone and anthraquinone related compounds. Chemical structures are shown. Hydroxyl groups are shown in blue and hydroxyl groups at para positions are in red (A). The antibiofilm activities of quinones and anthraquinones related compounds against $C$. albicans were determined after culturing for $24 \mathrm{~h}$ (B). Antibiofilm formation by selected compounds at low doses (C) none indicates non- treated samples. Two independent experiments were conducted (6 wells per sample); error bars indicate standard deviations. ${ }^{*} p<0.05$ vs. non-treated controls. 


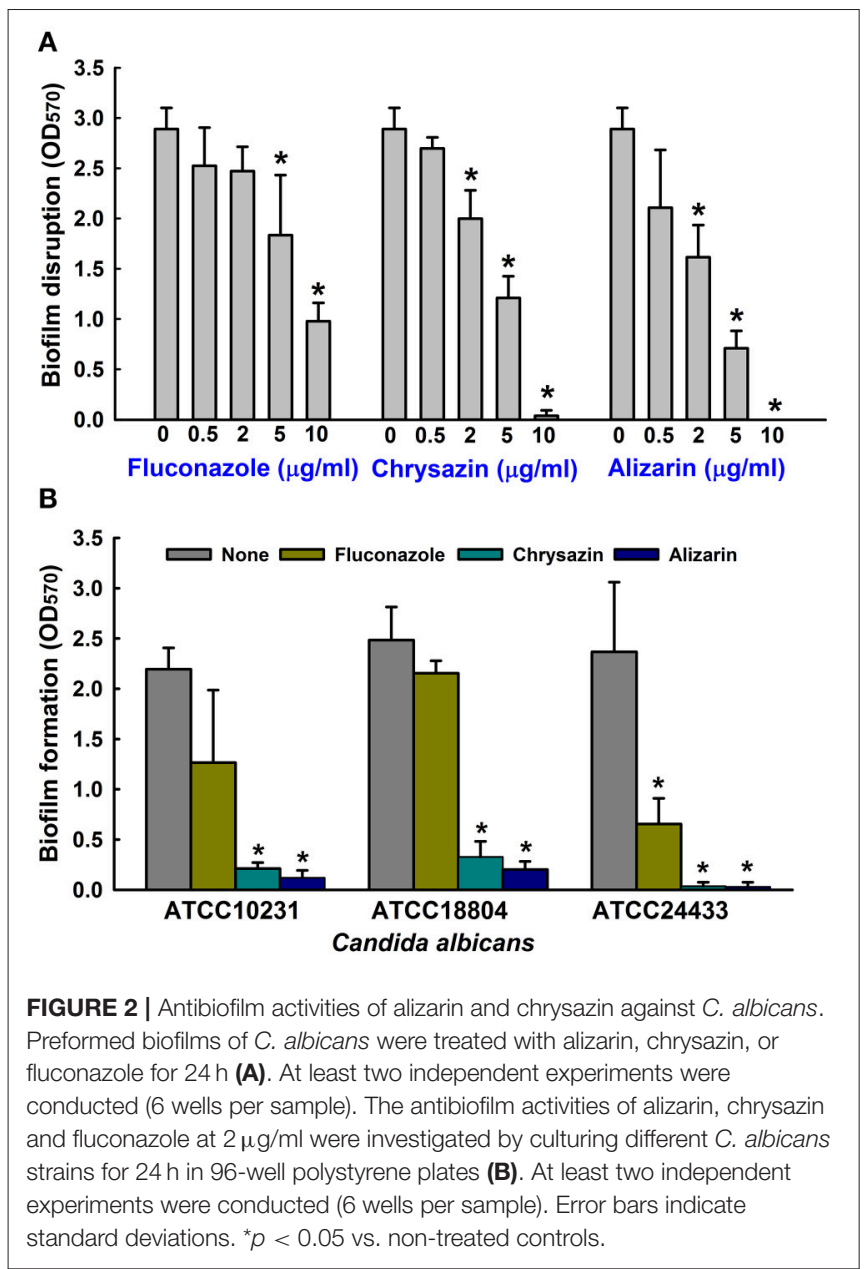

respectively after chrysazin $(2 \mu \mathrm{g} / \mathrm{ml})$ treatment. Nevertheless, HYR1 (hypha-specific gene) and EED1 (adhesive related gene) were not affected after alizarin treatment. Interestingly, ALS1 which involved in adhesion and biofilm formation was found to be upregulated by alizarin treatment. Similarly, the transcriptional level of hyphae regulatory gene EFG1 was increased after alizarin treatment. Taken together, qRT-PCR results showed that alizarin significantly altered the expression of some hypha-specific genes and adhesive related genes.

\section{Inhibition of Candida Virulence in the Nematode Caenorhabditis elegans}

The antibiofilm and antihyphal effects of alizarin and chrysazin were examined in C. elegans infected with C. albicans. Microscopic observations of infected nematodes revealed that C. albicans infection caused $95 \%$ fatality in 4 days. However, more than $60 \%$ of nematodes survived 4 days in the presence of alizarin $(2 \mu \mathrm{g} / \mathrm{ml}),>50 \%$ survived 4 days in the presence of chrysazin, $>60 \%$ survived 4 days in the presence of purpurin and $<50 \%$ survived 4 days in the presence of fluconazole (a commercial antifungal agent; Figure 8A). To examine the toxicities of alizarin and chrysazin, non-infected worms were

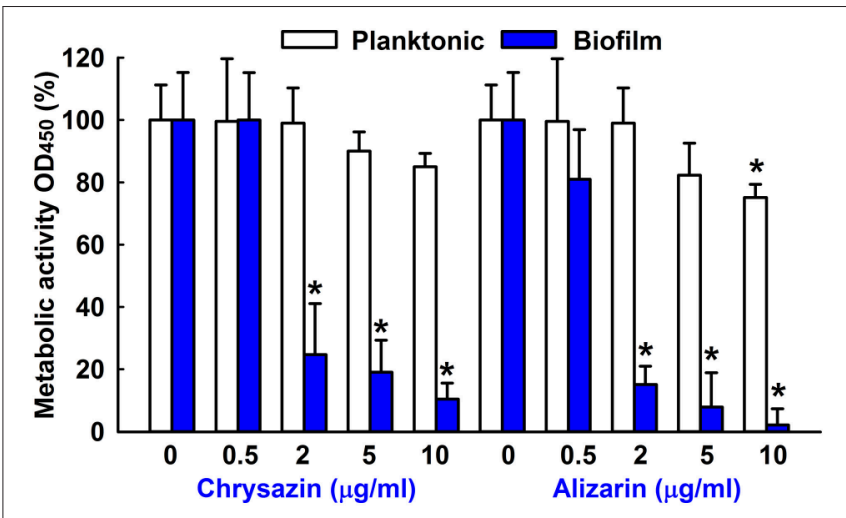

FIGURE 3 | Metabolic activity of alizarin and chrysazin against C. albicans. The metabolic activities of planktonic cells and biofilms of $C$. albicans were quantified using an XTT assay in the presence of alizarin and chrysazin after incubation for $24 \mathrm{~h}$. Results are presented as mean percent of metabolic activities vs. non-treated controls. Two independent experiments were conducted ( 6 wells per sample); error bars indicate standard deviations. None indicates non-treated samples. ${ }^{*} p<0.05$ vs. non-treated controls.

treated with different concentrations for 4 days. It was found alizarin at concentrations of $1 \mathrm{mg} / \mathrm{ml}$ did not affect nematode viability or survival (Figure 8B). However, at this concentration, chrysazin reduced nematodes survival by $>60 \%$ and purpurin reduced $35 \%$ survival rate, whereas only $<5 \%$ nematodes survived treatment with fluconazole at $1 \mathrm{mg} / \mathrm{ml}$ for 4 days. These results show alizarin was as effective as fluconazole at promoting the survival of infected nematodes, but that it was substantially less toxic.

\section{DISCUSSION}

The emergence of multidrug-resistant Candida strains and the limited efficacies of commercial antifungal treatments have prompted searches for new antifungals. In the present study, we sought to identify agents that inhibit biofilm formation by Candida without reducing its viability. Unlike antibiotics that usually inhibit cell growth, it is important to find biofilm inhibitors that do not affect fungal growth in order to reduce the chance of the development of drug resistance (Iwase et al., 2010). We found that the anthraquinones related compounds namely pyrocatechol, alizarin red, quinalizarin, emodin, 1hydroxyanthra-9,10-quinone, purpurin, chrysazin, and alizarin inhibited biofilm formation by C. albicans in a dose-dependent manner (Figure 1C). Many natural compounds have been tested and found to be effective against various bacterial and yeast virulence traits (De Castro et al., 2013; Hsu et al., 2013; Da Silva et al., 2016). Anthraquinones are usually found in higher plants like Rubia species (Usai and Marchetti, 2010; Xu et al., 2014), and several natural and synthetic anthraquinones derivatives have been shown to exhibit antimicrobial and antiinflammatory activities (Nor et al., 2013; Nam et al., 2017). Furthermore, anthraquinone derivatives like chrysazin have long been employed in medical preparations as laxatives, and most anthraquinones are relatively non-toxic to humans (Sendelbach, 
TABLE 1 | Minimum inhibitory concentration (MIC) of quinone and anthraquinone derivatives against C. albicans DAY185.

\begin{tabular}{|c|c|c|c|c|c|c|c|}
\hline Compounds & Alizarin & Alizarin red & Anthraflavic acid & Anthraquinone & (+)- Catechin & (+)- Catechin hydrate & Chrysazin \\
\hline $\mathrm{MIC}(\mathrm{mg} / \mathrm{ml})$ & $>2$ & $>5$ & 0.5 & $>5$ & 2.5 & $>5$ & $>2$ \\
\hline Compounds & Emodin & 1-Hydroxyanthra-9, 10-quinone & Hydroquinone & Purpurin & Pyrocatechol & Quinalizarin & \\
\hline $\mathrm{MIC}(\mathrm{mg} / \mathrm{ml})$ & 0.5 & $>5$ & $>5$ & 1.5 & 2 & 2.5 & \\
\hline
\end{tabular}

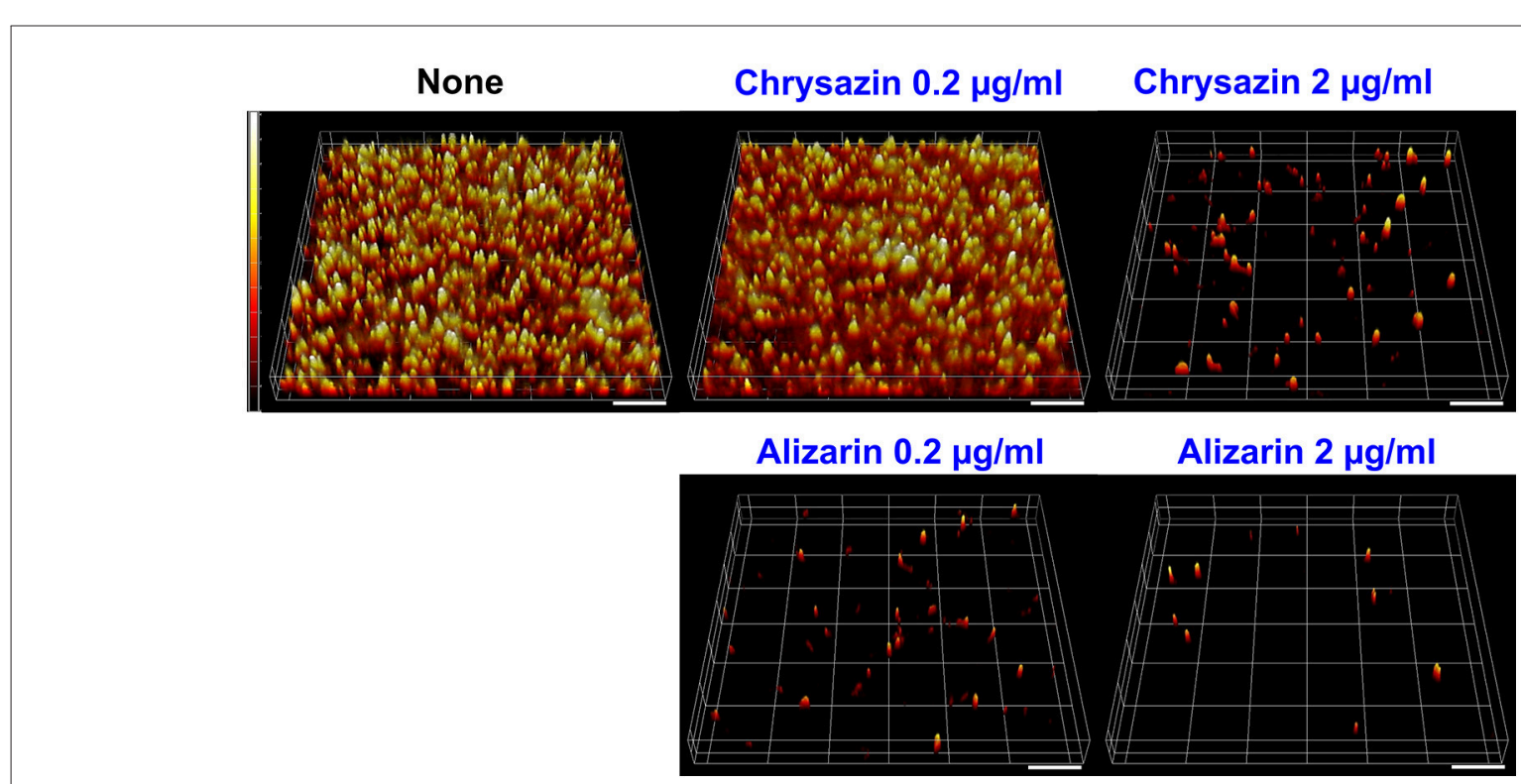

FIGURE 4 | Microscopic observations of the effects of alizarin and chrysazin on biofilms. Biofilm formation by $C$. albicans on polystyrene plates was observed in the presence of alizarin or chrysazin by confocal laser scanning microscopy. Scale bars represent $100 \mu \mathrm{m}$.

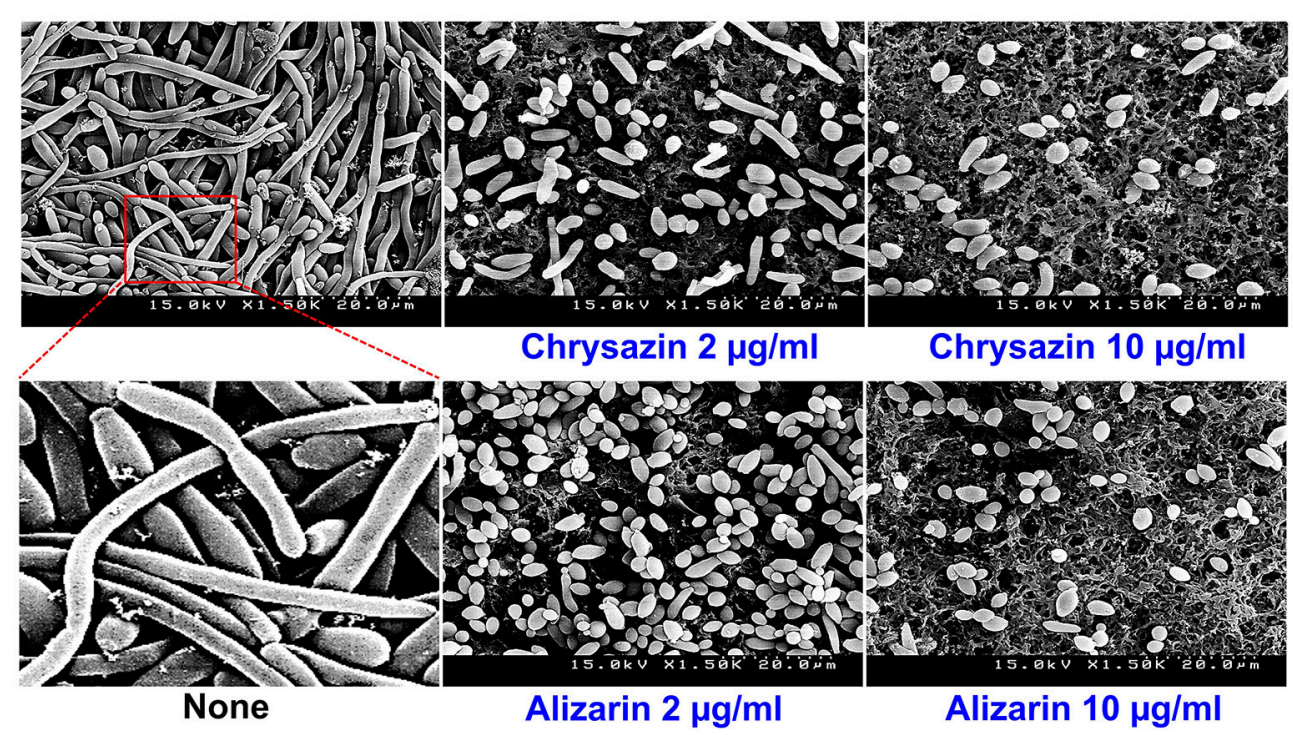

FIGURE 5 | Effects of alizarin and chrysazin on C. albicans morphology. Inhibition of hyphal growth was visualized by SEM at a concentration of 2 and $10 \mu \mathrm{g} / \mathrm{ml}$. The scale bar represents $20 \mu \mathrm{m}$. At least two independent experiments were conducted. None indicates non-treated controls.

1989; Nam et al., 2017). Previous study found that alizarin, purpurin and other anthraquinone derivatives significantly reduced $S$. aureus biofilms and virulence at a concentration of $2 \mu \mathrm{g} / \mathrm{ml}$ (Lee et al., 2016). The present study shows the anthraquinones alizarin and chrysazin possess potent antibiofilm activity against $C$. albicans strains. Furthermore, since C. albicans 


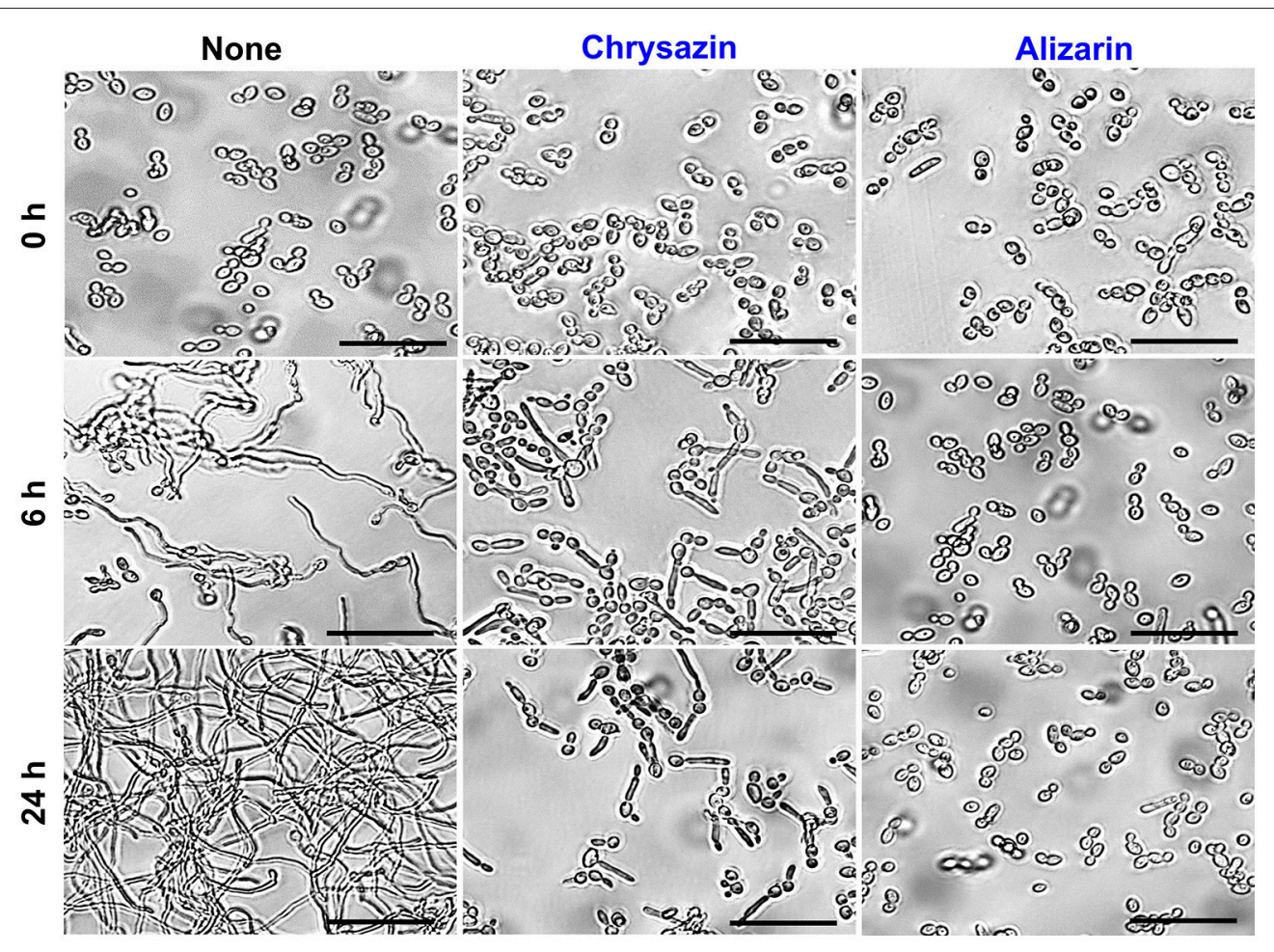

FIGURE 6 | Effects of alizarin and chrysazin on C. albicans hyphal growth on liquid media. C. albicans was grown in RPMI-1640 medium in the presence of $2 \mu \mathrm{g} / \mathrm{ml}$ alizarin or chrysazin at $37^{\circ} \mathrm{C}$ for $24 \mathrm{~h}$. Aliquots were withdrawn at different times and photographed using bright field microscope. The scale bar represents $50 \mu \mathrm{m}$.

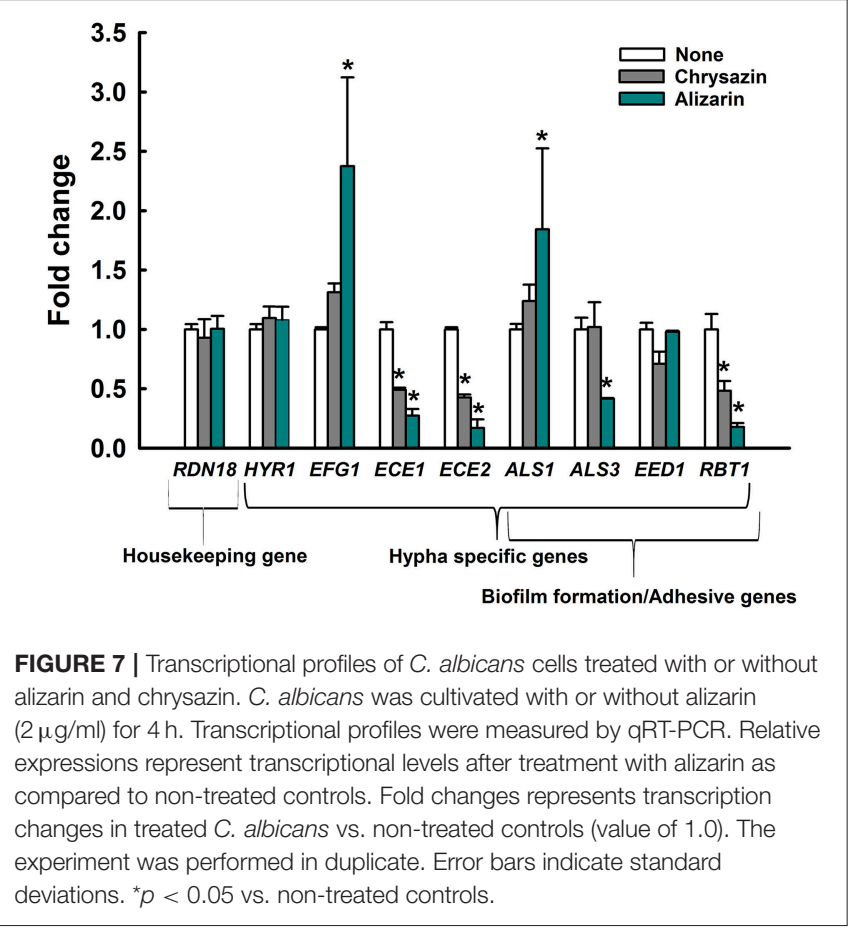

DAY185 is a fluconazole resistant strain, it would appear that alizarin, which is less toxic than fluconazole, offer a potential means of treatment.
Alizarin is a natural compound derived from the roots of the madder genus, and is used as a red dye in studies on bone growth, calcium deposits in vascular systems, and on gene expression in animal models (Puchtler et al., 1969). Recent study revealed that alizarin had strong in vitro activity against human bone tumor cells with lower toxicity to normal cells. In addition to anticancer properties, no tumor promoting or mutagenic activities have been found in human cell lines that suggests the use of alizarin in humans (Takahashi et al., 2002; Fotia et al., 2012). In the present study, alizarin inhibited $C$. albicans biofilm formation by $90 \%$ at a concentration of $2 \mu \mathrm{g} / \mathrm{ml}$, which was a 1,000-fold lower than its MIC for planktonic cells (Figure 1). The presence of aromatic hydroxyls on the anthraquinone ring of alizarin were probably largely responsible for its anti-fungal effect (Tian et al., 2003; Kim et al., 2004), which suggests the presence of $\mathrm{OH}$ groups at different positions may have been largely responsible for the different antibiofilm properties observed (Figure 1A). Anthraquinones with an $\mathrm{OH}$ group at the para position exhibited highest activity in all assays conducted. For example, purpurin, chrysazin, and alizarin with an $\mathrm{OH}$ group in the $\mathrm{C} 1$ position (indicated in red in Figure 1A) had showed strong inhibitory activity against $C$. albicans biofilms even at low concentrations $(2 \mu \mathrm{g} / \mathrm{ml})$. In addition to biofilm inhibition, alizarin and chrysazin dose-dependently disrupted matured biofilms (Figure 2A).

Recently, attempts have been made to identify small molecules that modulate hyphal formation by C. albicans (Midkiff et al., 2011; Grald et al., 2012; You et al., 2013). 


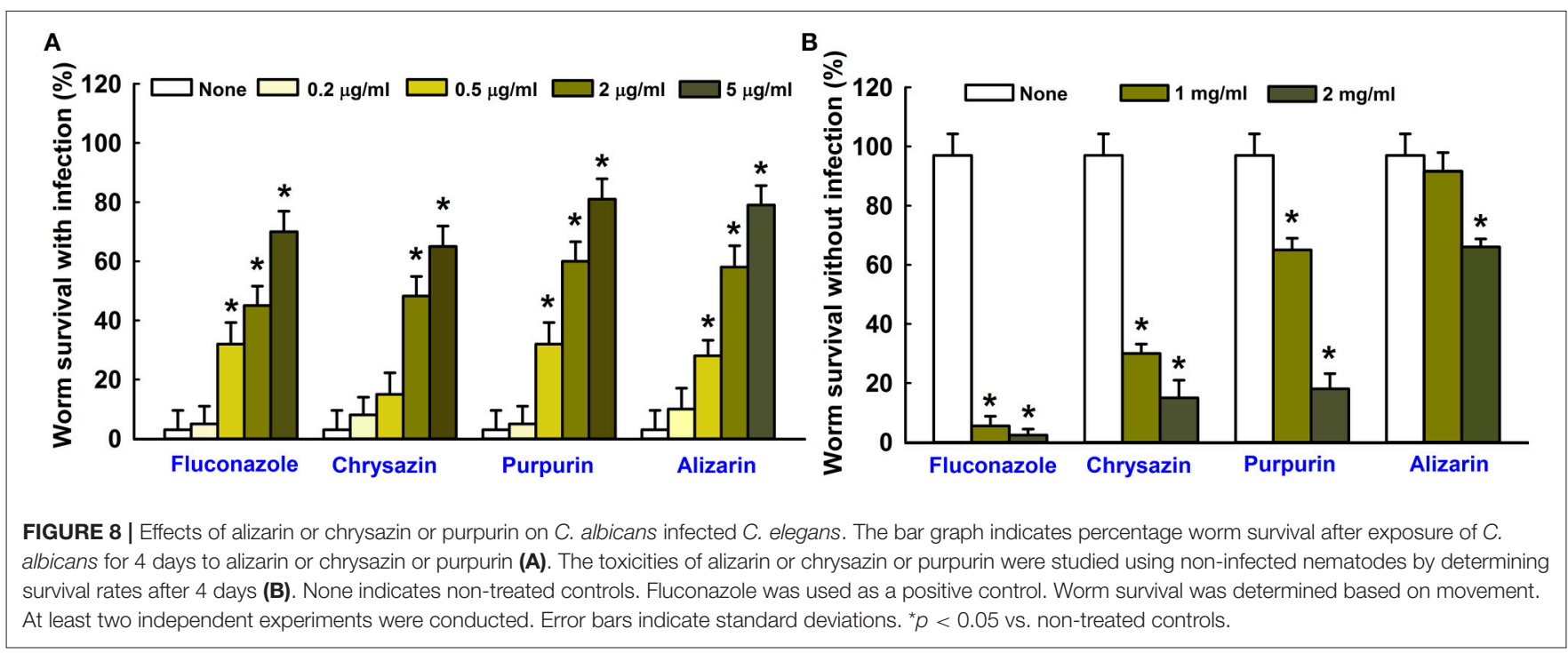

Cells that adhere to the surfaces of medical devices could develop biofilm layer, followed by hyphal transition and constitute a significant medical challenge (Kojic and Darouiche, 2004). Fully mature biofilms have a mixture of yeast, hyphae and pseudohyphae morphological forms in the extracellular matrix which suggested that transition of yeast to hyphal form is a directly correlated with development of structured biofilms (Nobile and Mitchell, 2005). Lower concentrations of purpurin $(3 \mu \mathrm{g} / \mathrm{ml})$ and emodin $(1.25 \mu \mathrm{g} / \mathrm{ml})$ have been reported previously for inhibiting the hyphal development against C. albicans (Tsang et al., 2012; Janeczko et al., 2017), whereas in the present study, alizarin had showed the same activity at $\sim 2 \mu \mathrm{g} / \mathrm{ml}$. Furthermore, alizarin and chrysazin at $2 \mu \mathrm{g} / \mathrm{ml}$ significantly disrupted mature biofilms (at $10 \mu \mathrm{g} / \mathrm{ml}$ both completely disrupted), whereas the antifungal fluconazole was less effective against $C$. albicans mature biofilms at this concentration (Figure 2A). In the present study, alizarin and chrysazin completely inhibited hyphal development even at a concentration of $2 \mu \mathrm{g} / \mathrm{ml}$ without affecting cell growth, which may indicate that both alizarin and chrysazin influence the pathway responsible for hyphal development (Figures 5, 6). The data suggest that alizarin and chrysazin suppress $C$. albicans dimorphic switching, which is in agreement with the biofilm development (Figures 4, 5).

The transcriptional levels of several hypha-specific genes were significantly altered in alizarin treated cells. More specifically, ECE1, ECE2 (or called HWP1) and RBT1 were downregulated after alizarin and chrysazin treatment (Figure 7). Our results were consistent with previous findings that purpurin reduced the transcription levels of hypha-specific genes such as ALS3, ECE1, HWP1 (Tsang et al., 2012). ALS3 had been reported as hypha-specific gene that considerably upregulated during initial stages of biofilm formation and hyphal development (Argimon et al., 2007). Another gene, ALS1 encodes cell-surface associated glycoproteins which had shown relatively downregulated during initial biofilm formation (Nailis et al., 2009). Consistently, in this study, an increase in ALS1 expression was noted after alizarin treatment, suggesting that alizarin might disturb biofilm formation at the initial stage. ECE1 encodes a protein required for hyphal cell elongation and biofilm formation (Nobile et al., 2006a), and ECE2 (HWP1) is essential for its hyphal development and cell adherence (Nobile et al., 2006b). HWP1 homolog gene, RBT1 expression correlates with hyphal formation and biofilm development (Braun et al., 2000). Our data suggest that alizarin and chrysazin inhibits hyphae and biofilm formation by downregulating these hypha-specific genes.

The protein encoded by EFG1 has a dual role as a transcriptional activator or repressor that controls hyphal morphogenesis. Accordingly, decline of EFG1 transcriptional level was correlated with the hyphal induction (Stoldt et al., 1997; Tebarth et al., 2003). Our results suggest that increase in the transcriptional level of EFG1 after alizarin treatment (Figure 7) may be due to a feedback loop that controls EFG1 expression during the maintenance phase of hyphal morphogenesis. Taken together, our results suggest that alizarin and chrysazin may inhibit cell adhesion, biofilm formation, and hyphal development by regulating the hypha-specific genes.

In the previous studies, we observed $C$. albicans cells readily enter the nematode intestine and kill worms, and that the presence of terpenes and terpenoids such as linalool, camphor, and $\alpha$-longipinene rescued infected nematodes (Manoharan et al., 2017a,b). In another study, terpenoids like gymnemic acid, and polyphenolic class of compounds such as magnolol and honokiol reduced $C$. albicans colonization in the body of nematodes and prolonged the survival rates (Vediyappan et al., 2013; Sun et al., 2015). Based on the observed higher survival rate of infected nematodes, our results suggest that alizarin and chrysazin effectively reduced $C$. albicans virulence in vivo (Figure 8A). Although, a correlation exists between compound toxicities in nematodes and mammals, the use of high concentrations of compounds in man is potentially hazardous 
(Williams and Dusenbery, 1988; Cole et al., 2004; Sochova et al., 2006). Animal toxicities of alizarin, chrysazin, and fluconazole showed that alizarin and chrysazin are less toxic than fluconazole while they prolonged the survival rates of nematodes (Figure 8). Our results suggest that alizarin and chrysazin could provide safe clinical approach in human system by treating biofilm associated C. albicans infections.

\section{CONCLUSION}

Present study shows alizarin and chrysazin inhibit biofilm formation and hyphal development by C. albicans. Accordingly, we suggest alizarin and chrysazin have potential use in vitro and in vivo, and that they offer potential means of treating candidiasis. We suggest that further in vivo experiments using mice model will confirm the potential applicability of alizarin and chrysazin against fluconazole resistant C. albicans, which could be alternative for commercially available and toxic antifungal agents.

\section{AUTHOR CONTRIBUTIONS}

RM and JL performed experiments, analyzed data, and wrote the manuscript. J-HL and JL designed the study and YK performed

\section{REFERENCES}

Alastruey-Izquierdo, A., Melhem, M. S., Bonfietti, L. X., and Rodriguez-Tudela, J. L. (2015). Susceptibility test for fungi: clinical and laboratorial correlations in medical mycology. Rev. Inst. Med. Trop. Sao Paulo 57(Suppl. 19), 57-64. doi: $10.1590 /$ S0036-46652015000700011

Amin-ul Mannan, M., Sharma, S., and Ganesan, K. (2009). Total RNA isolation from recalcitrant yeast cells. Anal. Biochem. 389, 77-79. doi: 10.1016/j.ab.2009.03.014

Argimon, S., Wishart, J. A., Leng, R., Macaskill, S., Mavor, A., Alexandris, T., et al. (2007). Developmental regulation of an adhesin gene during cellular morphogenesis in the fungal pathogen Candida albicans. Eukaryot. Cell 6, 682-692. doi: 10.1128/EC.00340-06

Braun, B. R., Head, W. S., Wang, M. X., and Johnson, A. D. (2000). Identification and characterization of TUP1-regulated genes in Candida albicans. Genetics $156,31-44$.

Cardoso, N. N., Alviano, C. S., Blank, A. F., Romanos, M. T., Fonseca, B. B., Rozental, S., et al. (2016). Synergism effect of the essential oil from Ocimum basilicum var. Maria Bonita and its major components with fluconazole and its influence on ergosterol biosynthesis. Evid. Based. Complement. Alternat. Med. 2016:5647182. doi: 10.1155/2016/5647182

Carradori, S., Chimenti, P., Fazzari, M., Granese, A., and Angiolella, L. (2016). Antimicrobial activity, synergism and inhibition of germ tube formation by Crocus sativus-derived compounds against Candida spp. J. Enzyme Inhib. Med. Chem. 31, 189-193. doi: 10.1080/14756366.2016.1180596

Cole, R. D., Anderson, G. L., and Williams, P. L. (2004). The nematode Caenorhabditis elegans as a model of organophosphate-induced mammalian neurotoxicity. Toxicol. Appl. Pharmacol. 194, 248-256. doi: 10.1016/j.taap.2003.09.013

Curvelo, J. A., Marques, A. M., Barreto, A. L., Romanos, M. T., Portela, M. B., Kaplan, M. A., et al. (2014). A novel nerolidol-rich essential oil from Piper claussenianum modulates Candida albicans biofilm. J. Med. Microbiol. 63(Pt 5), 697-702. doi: 10.1099/jmm.0.063834-0

Da Silva, A. P., Nascimento da Silva, L. C., Martins da Fonseca, C. S., de Araujo, J. M., Correia, M. T., Cavalcanti Mda, S., et al. (2016). Antimicrobial activity microscopic experiments. All authors have read and approved the final manuscript.

\section{ACKNOWLEDGMENTS}

This research was supported by the National Research Foundation of Korea (NRF) funded by the Korea government (MSIP) (\#2015R1A2A2A01004542 to JL), by the Basic Science Research Program through the NRF funded by the Ministry of Education (\#215C000232 to J-HL), and by the Priority Research Centers Program through the NRF funded by the Ministry of Education (\#2014R1A6A1031189).

\section{SUPPLEMENTARY MATERIAL}

The Supplementary Material for this article can be found online at: https://www.frontiersin.org/articles/10.3389/fcimb. 2017.00447/full\#supplementary-material

Supplementary Figure 1 | Antibiofilm activities of anthraquinone derivatives against mixed biofilms of $C$. albicans and $S$. aureus. The antibiofilm activities of alizarin, chrysazin, purpurin and fluconazole were investigated by co-culturing of C. albicans and $S$. aureus strains for $24 \mathrm{~h}$ in 96 -well polystyrene plates in mixed medium (50\% LB and $50 \% \mathrm{PDB}$ ) at $37^{\circ} \mathrm{C}$. At least two independent experiments were conducted (6 wells per sample). Error bars indicate standard deviations. $* p<0.05$ vs. non-treated controls. and phytochemical analysis of organic extracts from Cleome spinosa Jaqc. Front. Microbiol. 7:963. doi: 10.3389/fmicb.2016.00963

De Castro, P. A., Bom, V. L., Brown, N. A., de Almeida, R. S., Ramalho, L. N., Savoldi, M., et al. (2013). Identification of the cell targets important for propolis-induced cell death in Candida albicans. Fungal Genet. Biol. 60, 74-86. doi: 10.1016/j.fgb.2013.07.001

Fotia, C., Avnet, S., Granchi, D., and Baldini, N. (2012). The natural compound Alizarin as an osteotropic drug for the treatment of bone tumors. J. Orthop. Res. 30, 1486-1492. doi: 10.1002/jor.22101

Gauwerky, K., Borelli, C., and Korting, H. C. (2009). Targeting virulence: a new paradigm for antifungals. Drug Discov. Today 14, 214-222. doi: 10.1016/j.drudis.2008.11.013

Grald, A., Yargosz, P., Case, S., Shea, K., and Johnson, D. I. (2012). Small-molecule inhibitors of biofilm formation in laboratory and clinical isolates of Candida albicans. J. Med. Microbiol. 61(Pt 1), 109-114. doi: 10.1099/jmm.0.034124-0

Haque, F., Alfatah, M., Ganesan, K., and Bhattacharyya, M. S. (2016). Inhibitory effect of sophorolipid on Candida albicans biofilm formation and hyphal growth. Sci. Rep. 6:23575. doi: 10.1038/srep23575

Hsu, C. C., Lai, W. L., Chuang, K. C., Lee, M. H., and Tsai, Y. C. (2013). The inhibitory activity of linalool against the filamentous growth and biofilm formation in Candida albicans. Med. Mycol. 51, 473-482. doi: 10.3109/13693786.2012.743051

Iwase, T., Uehara, Y., Shinji, H., Tajima, A., Seo, H., Takada, K., et al. (2010). Staphylococcus epidermidis Esp inhibits Staphylococcus aureus biofilm formation and nasal colonization. Nature 465, 346-349. doi: 10.1038/nature09074

Janeczko, M., Maslyk, M., Kubinski, K., and Golczyk, H. (2017). Emodin, a natural inhibitor of protein kinase CK2, suppresses growth, hyphal development, and biofilm formation of Candida albicans. Yeast 34, 253-265. doi: $10.1002 /$ yea. 3230

Kang, K., Fong, W. P., and Tsang, P. W. (2010). Novel antifungal activity of purpurin against Candida species in vitro. Med. Mycol. 48, 904-911. doi: 10.3109/13693781003739351

Kim, Y.-G., Lee, J.-H., Kim, C. J., Lee, J. C., Ju, Y. J., Cho, M. H., et al. (2012). Antibiofilm activity of Streptomyces sp. BFI 230 and Kribbella sp. BFI 1562 
against Pseudomonas aeruginosa. Appl. Microbiol. Biotechnol. 96, 1607-1617. doi: 10.1007/s00253-012-4225-7

Kim, Y.-M., Lee, C.-H., Kim, H.-G., and Lee, H.-S. (2004). Anthraquinones isolated from Cassia tora (Leguminosae) seed show an antifungal property against phytopathogenic fungi. J. Agric. Food Chem. 52, 6096-6100. doi: 10.1021/jf049379p

Kojic, E. M., and Darouiche, R. O. (2004). Candida infections of medical devices. Clin. Microbiol. Rev. 17, 255-267. doi: 10.1128/CMR.17.2.255-267.2004

Lee, J.-H., Cho, M. H., and Lee, J. (2011). 3-Indolylacetonitrile decreases Escherichia coli O157:H7 biofilm formation and Pseudomonas aeruginosa virulence. Environ. Microbiol. 13, 62-73. doi: 10.1111/j.1462-2920.2010.02308.x

Lee, J.-H., Kim, Y.-G., Yong Ryu, S., and Lee, J. (2016). Calcium-chelating alizarin and other anthraquinones inhibit biofilm formation and the hemolytic activity of Staphylococcus aureus. Sci. Rep. 6:19267. doi: 10.1038/srep19267

Lee, K., Lee, J.-H., Kim, S. I., Cho, M. H., and Lee, J. (2014). Anti-biofilm, antihemolysis, and anti-virulence activities of black pepper, cananga, myrrh oils, and nerolidol against Staphylococcus aureus. Appl. Microbiol. Biotechnol. 98, 9447-9457. doi: 10.1007/s00253-014-5903-4

Manoharan, R. K., Lee, J.-H., Kim, Y.-G., Kim, S. I., and Lee, J. (2017a). Inhibitory effects of the essential oils $\alpha$-longipinene and linalool on biofilm formation and hyphal growth of Candida albicans. Biofouling 33, 143-155. doi: 10.1080/08927014.2017.1280731

Manoharan, R. K., Lee, J. H., and Lee, J. (2017b). Antibiofilm and antihyphal activities of cedar leaf essential oil, camphor, and fenchone derivatives against Candida albicans. Front. Microbiol. 8:1476. doi: 10.3389/fmicb.2017.01476

Marioni, J., da Silva, M. A., Cabrera, J. L., Montoya, S. C., and Paraje, M. G. (2016). The anthraquinones rubiadin and its 1-methyl ether isolated from Heterophyllaea pustulata reduces Candida tropicalis biofilms formation. Phytomedicine 23, 1321-1328. doi: 10.1016/j.phymed.2016.07.008

Midkiff, J., Borochoff-Porte, N., White, D., and Johnson, D. I. (2011). Small molecule inhibitors of the Candida albicans budded-to-hyphal transition act through multiple signaling pathways. PLOS ONE 6:e25395. doi: 10.1371/journal.pone.0025395

Morales, D. K., Grahl, N., Okegbe, C., Dietrich, L. E., Jacobs, N. J., and Hogan, D. A. (2013). Control of Candida albicans metabolism and biofilm formation by Pseudomonas aeruginosa phenazines. MBio 4, e00526-e00512. doi: 10.1128/mBio.00526-12

Murphy, C. T., McCarroll, S. A., Bargmann, C. I., Fraser, A., Kamath, R. S., Ahringer, J., et al. (2003). Genes that act downstream of DAF-16 to influence the lifespan of Caenorhabditis elegans. Nature 424, 277-283. doi: 10.1038/nature01789

Nailis, H., Vandenbroucke, R., Tilleman, K., Deforce, D., Nelis, H., and Coenye, T. (2009). Monitoring ALS1 and ALS3 gene expression during in vitro Candida albicans biofilm formation under continuous flow conditions. Mycopathologia 167, 9-17. doi: 10.1007/s11046-008-9148-6

Nam, W., Kim, S. P., Nam, S. H., and Friedman, M. (2017). Structureantioxidative and anti-inflammatory activity relationships of purpurin and related anthraquinones in chemical and cell assays. Molecules 22:E265. doi: 10.3390/molecules22020265

Nett, J. E., Cain, M. T., Crawford, K., and Andes, D. R. (2011). Optimizing a Candida biofilm microtiter plate model for measurement of antifungal susceptibility by tetrazolium salt assay. J. Clin. Microbiol. 49, 1426-1433. doi: 10.1128/JCM.02273-10

Nobile, C. J., Andes, D. R., Nett, J. E., Smith, F. J., Yue, F., Phan, Q. T., et al. (2006a). Critical role of Bcrl-dependent adhesins in C. albicans biofilm formation in vitro and in vivo. PLoS Pathog. 2:e63. doi: 10.1371/journal.ppat.0020063

Nobile, C. J., and Mitchell, A. P. (2005). Regulation of cell-surface genes and biofilm formation by the C. albicans transcription factor Bcr1p. Curr. Biol. 15, 1150-1155. doi: 10.1016/j.cub.2005.05.047

Nobile, C. J., Nett, J. E., Andes, D. R., and Mitchell, A. P. (2006b). Function of Candida albicans adhesin Hwp1 in biofilm formation. Eukaryot. Cell 5, 1604-1610. doi: 10.1128/EC.00194-06

Nor, S. M., Sukari, M. A., Azziz, S. S., Fah, W. C., Alimon, H., and Juhan, S. F. (2013). Synthesis of new cytotoxic aminoanthraquinone derivatives via nucleophilic substitution reactions. Molecules 18, 8046-8062. doi: 10.3390/molecules18078046

Oh, S., Go, G. W., Mylonakis, E., and Kim, Y. (2012). The bacterial signalling molecule indole attenuates the virulence of the fungal pathogen Candida albicans. J. Appl. Microbiol. 113, 622-628. doi: 10.1111/j.1365-2672.2012.05372.x

Pierce, C. G., Chaturvedi, A. K., Lazzell, A. L., Powell, A. T., Saville, S. P., McHardy, S. F., et al. (2015). A novel small molecule inhibitor of Candida albicans biofilm formation, filamentation and virulence with low potential for the development of resistance. NPJ Biofilms Microbiomes 1:15012. doi: 10.1038/npjbiofilms. 2015.12

Puchtler, H., Meloan, S. N., and Terry, M. S. (1969). On the history and mechanism of alizarin and alizarin red S stains for calcium. J. Histochem. Cytochem. 17, 110-124. doi: 10.1177/17.2.110

Rajasekharan, S. K., Ramesh, S., and Bakkiyaraj, D. (2015). Synergy of flavonoids with HDAC inhibitor: new approach to target Candida tropicalis biofilms. J. Chemother. 27, 246-249. doi: 10.1179/1973947814Y.0000000186

Ramage, G., Saville, S. P., Thomas, D. P., and Lopez-Ribot, J. L. (2005). Candida biofilms: an update. Eukaryot. Cell 4, 633-638. doi: 10.1128/EC.4.4.633-638.2005

Ramage, G., Vande Walle, K., Wickes, B. L., and Lopez-Ribot, J. L. (2001). Standardized method for in vitro antifungal susceptibility testing of Candida albicans biofilms. Antimicrob. Agents Chemother. 45, 2475-2479. doi: 10.1128/AAC.45.9.2475-2479.2001

Reen, F. J., Phelan, J. P., Gallagher, L., Woods, D. F., Shanahan, R. M., Cano, R., et al. (2016). Exploiting interkingdom interactions for development of smallmolecule inhibitors of Candida albicans biofilm formation. Antimicrob. Agents Chemother. 60, 5894-5905. doi: 10.1128/AAC.00190-16

Sandai, D., Tabana, Y. M., Ouweini, A. E., and Ayodeji, I. O. (2016). Resistance of Candida albicans biofilms to drugs and the host immune system. Jundishapur J. Microbiol. 9:e37385. doi: 10.5812/jjm.37385

Sardi, J. C., Scorzoni, L., Bernardi, T., Fusco-Almeida, A. M., and Mendes Giannini, M. J. (2013). Candida species: current epidemiology, pathogenicity, biofilm formation, natural antifungal products and new therapeutic options. J. Med. Microbiol. 62(Pt 1), 10-24. doi: 10.1099/jmm.0.045054-0

Sendelbach, L. E. (1989). A review of the toxicity and carcinogenicity of anthraquinone derivatives. Toxicology 57, 227-240. doi: 10.1016/0300-483X(89)90113-3

Sochova, I., Hofman, J., and Holoubek, I. (2006). Using nematodes in soil ecotoxicology. Environ. Int. 32, 374-383. doi: 10.1016/j.envint.2005. 08.031

Souza, C. M., Pereira Junior, S. A., Moraes Tda, S., Damasceno, J. L., Amorim Mendes, S., Dias, H. J., et al. (2016). Antifungal activity of plant-derived essential oils on Candida tropicalis planktonic and biofilms cells. Med. Mycol. 54, 515-523. doi: 10.1093/mmy/myw003

Stoldt, V. R., Sonneborn, A., Leuker, C. E., and Ernst, J. F. (1997). Efglp, an essential regulator of morphogenesis of the human pathogen Candida albicans, is a member of a conserved class of bHLH proteins regulating morphogenetic processes in fungi. EMBO J. 16, 1982-1991. doi: 10.1093/emboj/16.8.1982

Sun, L., Liao, K., and Wang, D. (2015). Effects of magnolol and honokiol on adhesion, yeast-hyphal transition, and formation of biofilm by Candida albicans. PLoS ONE 10:e0117695. doi: 10.1371/journal.pone.0117695

Taff, H. T., Mitchell, K. F., Edward, J. A., and Andes, D. R. (2013). Mechanisms of Candida biofilm drug resistance. Future Microbiol. 8, 1325-1337. doi: $10.2217 /$ fmb.13.101

Takahashi, E., Fujita, K.-i., Kamataki, T., Arimoto-Kobayashi, S., Okamoto, K., and Negishi, T. (2002). Inhibition of human cytochrome P450 1B1, 1A1 and 1A2 by antigenotoxic compounds, purpurin and alizarin. Mutat. Res. Fund. Mol. Mech. Mut. 508, 147-156. doi: 10.1016/S0027-5107(02)00212-9

Tebarth, B., Doedt, T., Krishnamurthy, S., Weide, M., Monterola, F., Dominguez, A., et al. (2003). Adaptation of the Efglp morphogenetic pathway in Candida albicans by negative autoregulation and PKA-dependent repression of the EFG1 gene. J. Mol. Biol. 329, 949-962. doi: 10.1016/S0022-2836(03)00505-9

Tian, B., Hua, Y. J., Ma, X. Q., and Wang, G. L. (2003). Relationship between antibacterial activity of aloe and its anthaquinone compounds. Zhongguo Zhong Yao Za Zhi 28, 1034-1037.

Tsang, P. W., Bandara, H. M., and Fong, W. P. (2012). Purpurin suppresses Candida albicans biofilm formation and hyphal development. PLoS ONE 7:e50866. doi: 10.1371/journal.pone.0050866

Usai, M., and Marchetti, M. (2010). Anthraquinone distribution in the hypogeal apparatus of Rubia peregrina L. growing wild in Sardinia. Nat. Prod. Res. 24, 626-632. doi: 10.1080/14786410902884842 
Vediyappan, G., Dumontet, V., Pelissier, F., and d'Enfert, C. (2013). Gymnemic acids inhibit hyphal growth and virulence in Candida albicans. PLoS ONE 8:e74189. doi: 10.1371/journal.pone.0074189

Weston, S. A., and Parish, C. R. (1990). New fluorescent dyes for lymphocyte migration studies. Analysis by flow cytometry and fluorescence microscopy. J. Immunol. Methods 133, 87-97. doi: 10.1016/0022-1759(90)90322-M

Williams, P. L., and Dusenbery, D. B. (1988). Using the nematode Caenorhabditis elegans to predict mammalian acute lethality to metallic salts. Toxicol. Ind. Health 4, 469-478. doi: 10.1177/074823378800400406

Xiang, W., Song, Q.-S., Zhang, H.-J., and Guo, S.-P. (2008). Antimicrobial anthraquinones from Morinda angustifolia. Fitoterapia 79, 501-504. doi: 10.1016/j.fitote.2008.04.008

Xu, K., Wang, P., Wang, L., Liu, C., Xu, S., Cheng, Y., et al. (2014). Quinone derivatives from the genus Rubia and their bioactivities. Chem. Biodivers. 11, 341-363. doi: 10.1002/cbdv.201200173
You, J., Du, L., King, J. B., Hall, B. E., and Cichewicz, R. H. (2013). Small-molecule suppressors of Candida albicans biofilm formation synergistically enhance the antifungal activity of amphotericin B against clinical Candida isolates. ACS Chem. Biol. 8, 840-848. doi: 10.1021/cb400009f

Conflict of Interest Statement: The authors declare that the research was conducted in the absence of any commercial or financial relationships that could be construed as a potential conflict of interest.

Copyright (c) 2017 Manoharan, Lee, Kim and Lee. This is an open-access article distributed under the terms of the Creative Commons Attribution License (CC BY). The use, distribution or reproduction in other forums is permitted, provided the original author(s) or licensor are credited and that the original publication in this journal is cited, in accordance with accepted academic practice. No use, distribution or reproduction is permitted which does not comply with these terms. 